\title{
Lumbopelvic alignment and sagittal balance in asymptomatic children and adoslescents
}

\author{
Mesquita PVD ${ }^{1}$, Ribeiro RP2*, Sedrez JA ${ }^{3}$ and Candotti $\mathrm{CT}^{4}$ \\ ${ }^{1}$ Physiotherapist, Master in science of the human movement by Federal University of Rio Grande do Sul (UFRGS) \\ ${ }^{2}$ Physiotherapist, research associate (UFRGS) \\ ${ }^{3}$ Physiotherapist, Doctoral student in science of the human movement at UFRGS \\ ${ }^{4} \mathrm{PhD}$ in Human Movement Sciences and Professor of Physiotherapy and Physical Education Courses at UFRGS
}

\begin{abstract}
The maintenance of bipedal posture is strongly influenced by the balance between the vertebral column and the pelvis. However, there are currently no studies reporting the relationships between sagittal trunk balance and lumbopelvic alignment in healthy children and adolescents, as well as the characteristics and correlations. Therefore the objective of this work was: to describe values of the variables of lombopelvic alignment in asymptomatic children and adolescents, as well as to verify the correlations between the measures of sagittal balance, sacral inclination, lumbar lordosis and thoracic kyphosis, regarding the age range of the sample and sex. Were included 39 panoramic digital radiographs in orthostasis of the spine in the right profile incidence in children and adolescents. The variables measured were: thoracic kyphosis, lumbar lordosis, sacral inclination and sagittal balance. Intra- and inter-rater reproducibility was performed with 10 randomly selected exams 1 week after initial collection. For better understanding the sample was stratified in sex and age group. The sacral inclination variable showed a significant and high correlation with lumbar lordosis in the total sample $(r=0.664, p<0.001)$, in the female group $(r=0.665, p=0.018)$ and in the age group stratifications $(r=0.667$; $\mathrm{p}=0.001$ and $\mathrm{p}=0.005)$. Being still very high in the male group $(\mathrm{r}=0.732, \mathrm{p}<0.001)$. Sacral inclination also showed significant results with sagittal balance, with a moderate correlation $(r=0.325, p=0.04)$. There was a correlation between sacral inclination and lumbar lordosis, for all the stratifications of the sample, and also with the sagittal balance analyzing the total sample.
\end{abstract}

\section{Introduction}

The maintenance of the bipedal posture is strongly influenced by the balance between the spine and the pelvis [1]. The spine, in the sagittal plane, presents physiological anteroposterior curvatures, whose alignment can be determined by parameters derived from the pelvic orientation and lumbar lordosis. Despite known variability of these parameters among individuals, studies have demonstrated consistent correlations in healthy adult populations, known as lombopelvic alignment [2-5]. In addition, pelvic orientation is closely related to the sagittal balance of the trunk in adults [2,6-8].

In the case of the child population, values for sagittal curvatures in adolescents and children have been documented [9-12], others have characterized the pelvic orientation and its morphology in this same plane $[8,9,11,13]$. However, there are currently no studies reporting the relationships between sagittal trunk balance and lumbopelvic alignment in healthy children and adolescents, as well as the characteristics and correlations. Detailed information such as these would be efficient for the identification and evaluation of deformities, until the most appropriate treatment is conducted.

The purpose of this study is to describe the values of the variables of lumbopelvic alignment in asymptomatic children and adolescents, as well as to verify the correlations between sagittal balance, sacral inclination, lumbar lordosis and thoracic kyphosis, as well as the age range of the sample and as to sex.

\section{Materials and methods}

\section{Sample}

Radiographic examinations of 41 children and adolescents were included, of which two were excluded because there were six lumbar vertebrae. This study was approved by the Research Ethics Committee of the Federal University of Rio Grande do Sul, under number 19685 and respected Resolution No. 466/12 of the National Health Council. Children were included after agreeing to their participation in the study and after signature of the Free and Informed Consent Form by their parents or guardians

\section{Radiographic Examinations}

Panoramic digital radiographs of the spine in the right profile were performed with children and adolescents in orthostasis with flexion of the shoulders and elbows in order to avoid overlapping of the humerus in the vertebral column.

Correspondence to: Ribeiro RP, Physiotherapist, research associate (UFRGS), São Vicente 500/201- Santa Cecília, Porto Alegre, RS, Brazil, Tel: 55051 999947565; E-mail: rpaivaribeiro2@gmail.com

Key words: Child, Adolescent Behavior, Posture, Physical Therapy Specialty, $X$-Rays

Received: March 16, 2018; Accepted: March 26, 2018; Published: March 29, 2018 
From the radiographs, Cobb angle calculations were performed in MATLAB $^{\circ} 7.9$ software. The angle of the thoracic kyphosis (Figure 1a) was obtained by marking the upper plateaus of T1 and lower T12, specifically two points in the anterior and posterior superior angles of $\mathrm{T} 1$ and two other points in the anterior and posterior inferior angles of T12. From these references, adjacent lines were drawn towards the concavity of the curvature. The meeting of these lines defined the Cobb angle for kyphosis. The same procedure was performed using the plateaus of L1 and L5, thus also defining the angle of the lumbar curvature (Figure 1b). However, if the extremities of the selected vertebrae were not well visible, the adjacent vertebrae above or below were used as alternatives to define the angle of curvature.

The sacral inclination (Figure 1c) was defined by the angle formed between the upper plateau line S1 and a horizontal line [6]. The sagittal balance of the trunk was determined using the vertical line method of C7 (Figure 1c), tracing a vertical line of the C7 barycenter and projecting it distally to its intersection with the horizontal line relative to the anterior superior horn of the sacrum. The distance in the horizontal line from the anterior horn of the sacrum to the point of intersection determines the magnitude of the axis. Positive values describe a previous instability, while negative values refer to a posterior instability [2].

\section{Reproducibility Intra and Inter-rater}

A total of 10 exams were randomly selected, which were analyzed again after one week by the same evaluator, to test the intra-rater reproducibility. The same exams were evaluated by two other evaluators, to test inter-rater reproducibility. The evaluations were carried out independently and the evaluators were not aware of the other results.

Intra-class correlation coefficient (ICC) was used for intra and inter-rater reproducibility analysis. The ICC values were classified as weak (ICC $<0,40$ ), moderate (ICC between 0,4 and 0,75 ) and excellent (ICC>0,75) according to Fleiss [14].

The data presented excellent inter-rater reproducibility for lordosis (ICC $=0,924 ;$ IC $=0,779-0,980 ; \mathrm{p}<0,001)$ and sagittal balance (ICC $=$ $0,871 ; \mathrm{IC}=0,623-0,965 ; \mathrm{p}<0,001)$. Sacral inclination (ICC $=0,637$; IC $=-0,065-0,902 ; \mathrm{p}=0,032)$ and thoracic kyphosis $(\mathrm{ICC}=0,691 ; \mathrm{IC}=$ $0,093-0,916 ; p=0,016)$ were classified as moderate. In the intra-rater analysis, all variables obtained excellent reproducibility, ranging from ICC $=0,971$ and IC $=0,885-0,993$ to ICC $=0,995$ and IC $=0,978-0,999$, always with $\mathrm{p}<0,001$.

a)
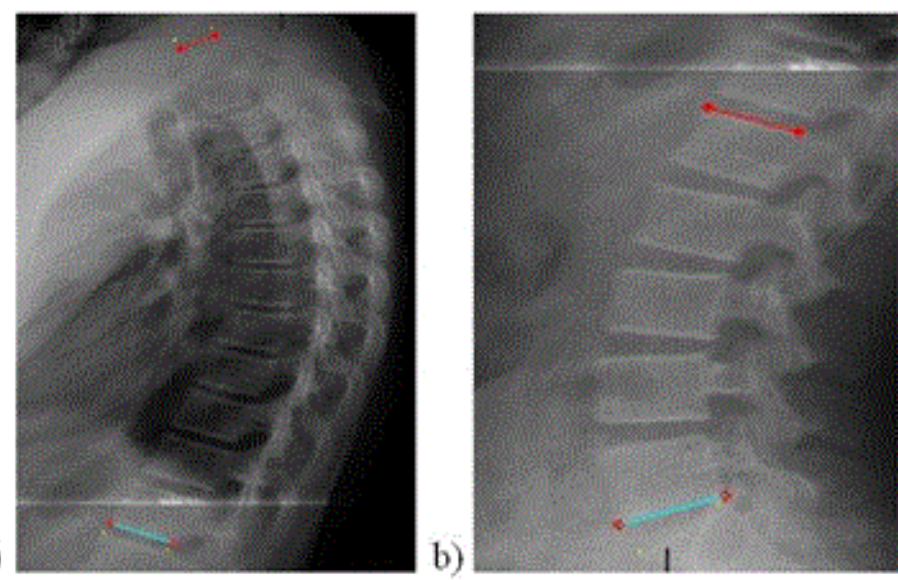

c)

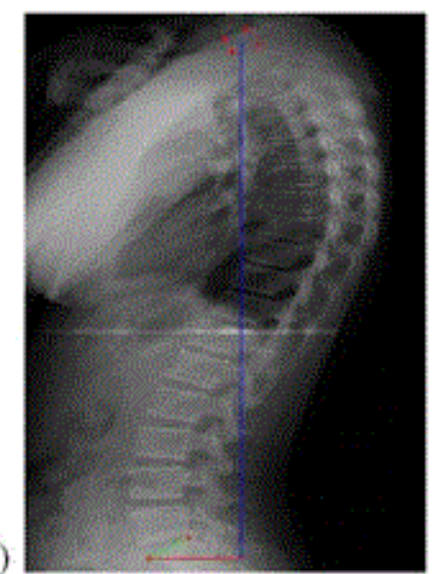

Figure 1. Analysis of spine radiographic exames to calculate Cobb curvatures angles (a) thoracic kyphosis, (b) lumber lordosis, and (c) sacral inclination angle and sagittal balance assessment.

\section{Statistical Treatment}

In the SPSS 20.0 software verified the normality of data with the Shapiro-Wilk test and the descriptive analysis was performed using mean and standard deviation values.

For the correlation of the variables of lumbopelvic alignment and sagittal balance of the spine, the Pearson Product-moment Correlation Coefficient ( $r$ ) and paired t-test were used. The Pearson correlation coefficient (r) was classified as very low (between 0,0 and 0,1 ), low (between 0,1 and 0,3 ), moderate (between 0,3 and 0,5 ), high (between 0,5 and 0,7 ), very high (between 0,7 and 0,9 ) and practically perfect (between 0,9 and 1,0) according to Hopkins [15]. The level of significance was set at 0,05 .

\section{Results}

The sample consisted of 39 radiographic examinations of children and adolescents, with a mean age of $12,3 \pm 3,2$. The characterization of the individuals evaluated and the mean values of the radiographic analysis are presented in Table 1.

Table 2 presents the values obtained through the Pearson correlation between the variables of lumbopelvic alignment and sagittal balance stratified by sex, age group and total sample.

\section{Discussion}

The variable sacral inclination showed a significant and high correlation with lumbar lordosis in the total sample $(r=0,664 ; p$ $<0.001)$, in the female group $(\mathrm{r}=0,665 ; \mathrm{p}=0,018)$ and in the age group stratifications $(\mathrm{r}=0,667 ; \mathrm{p}=0,001$ and $\mathrm{p}=0,005)$. Being still very high in the male group $(r=0,732 ; p<0,001)$. Sacral inclination also showed significant results with sagittal balance, with a moderate correlation ( $\mathrm{r}$ $=0,325 ; \mathrm{p}=0,04)$.

The study found that both boys and girls presented a correlation between the sacral inclination and lumbar lordosis, regardless of age stratification, although this appears to be higher in males. Masharawi, et al. [16] performed measures of lumbar lordosis (LL), angle (L1-S1), and sacral inclination (SS), angle formed between the upper plateau line of $\mathrm{S} 1$ and a horizontal line, in the supine position by magnetic resonance imaging in 100 asymptomatic children and adolescents, which were repeated after 3 years. Inittialy the girls showed higher LL and SS $\left(45,2^{\circ}\right.$ and $33,6^{\circ}$, respectively) than boys $\left(40,7^{\circ}\right.$ and $31,4^{\circ}$, respectively), but with the follow up, both LL and SS became higher 
Table 1. Mean, standard deviation (SD) and t-test of the sample characterization variables and the parameters of lumbopelvic alignment and sagittal balance, stratified by sex, age group and total sample.

\begin{tabular}{|c|c|c|c|c|c|c|c|}
\hline \multirow{3}{*}{ Variables } & \multirow{3}{*}{$\begin{array}{c}\begin{array}{c}\text { Total Sample } \\
(\mathrm{n}=39)\end{array} \\
\text { Mean } \pm \text { SD }\end{array}$} & \multicolumn{3}{|c|}{ Sex } & \multicolumn{3}{|c|}{ Age group } \\
\hline & & \multirow{2}{*}{$\begin{array}{c}\begin{array}{c}\text { Male } \\
(\mathrm{n}=26)\end{array} \\
\text { Mean } \pm \text { SD }\end{array}$} & \multirow{2}{*}{$\begin{array}{c}\begin{array}{c}\text { Female } \\
(\mathrm{n}=13)\end{array} \\
\text { Mean } \pm \mathbf{S} \mathbf{D}\end{array}$} & \multirow[t]{2}{*}{$\underset{\text { (t-test) }}{\mathbf{p}}$} & $\begin{array}{c}\text { Up to } 11 \text { years } \\
(\mathrm{n}=16)\end{array}$ & $\begin{array}{c}\text { From } 12 \text { to } 18 \\
\text { years } \\
(\mathrm{n}=23)\end{array}$ & \multirow[t]{2}{*}{$\underset{\text { (t-test) }}{\mathbf{p}}$} \\
\hline & & & & & Mean \pm SD & Mean \pm SD & \\
\hline Body Mass (kg) & $45.2 \pm 12.9$ & $45.9 \pm 12.6$ & $43.9 \pm 13.9$ & 0.612 & $35.3 \pm 11.6$ & $51.5 \pm 9.4$ & 0.000 \\
\hline Height (cm) & $1.4 \pm 0.2$ & $1.5 \pm 0.1$ & $1.5 \pm 0.2$ & 0.815 & $1.3 \pm 0.1$ & $1.6 \pm 0.1$ & 0.000 \\
\hline Body mass index $\left(\mathrm{kg} / \mathrm{cm}^{2}\right)$ & $20.6 \pm 3.8$ & $21.0 \pm 4.0$ & $19.9 \pm 3.3$ & 0.467 & $20.1 \pm 5.5$ & $20.9 \pm 2.3$ & 0.455 \\
\hline Sacral inclination $\left({ }^{\circ}\right)$ & $36.9 \pm 9.1$ & $38.1 \pm 9.5$ & $34.4 \pm 8.1$ & 0.552 & $34.9 \pm 9.0$ & $38.4 \pm 9.2$ & 0.870 \\
\hline Sagittal balance (cm) & $-1.9 \pm 3.1$ & $-1.6 \pm 3.3$ & $-2.8 \pm 2.5$ & 0.184 & $-2.7 \pm 2.7$ & $-1.4 \pm 3.4$ & 0.408 \\
\hline Thoracic Kyphosis $\left({ }^{\circ}\right)$ & $48.8 \pm 10.6$ & $48.1 \pm 10.2$ & $50.6 \pm 11.7$ & 0.848 & $47.3 \pm 9.1$ & $50.0 \pm 11.6$ & 0.447 \\
\hline Lumbar Lordosis $\left({ }^{\circ}\right)$ & $42.5 \pm 7.3$ & $42.6 \pm 6.1$ & $42.6 \pm 9.9$ & 0.064 & $42.0 \pm 6.6$ & $43.0 \pm 7.9$ & 0.684 \\
\hline
\end{tabular}

Table 2. Parameters of lumbopelvic alignment and sagittal balance related to sex, age group and total sample.

\begin{tabular}{|c|c|c|c|c|c|}
\hline \multirow[b]{2}{*}{ Parameters } & \multirow[b]{2}{*}{ Total sample } & \multicolumn{2}{|c|}{ Sex } & \multicolumn{2}{|c|}{ Age group } \\
\hline & & Female & Male & Up to 11 years & From 12 to 18 years \\
\hline & $(n=39)$ & $(\mathrm{n}=13)$ & $(n=26)$ & $(n=16)$ & $(\mathrm{n}=23)$ \\
\hline Kyphosis x Lordosis & $0.07(\mathrm{p}=0.968)$ & $-0.299(\mathrm{p}=0.344)$ & $0.247(\mathrm{p}=0.215)$ & $0.081(\mathrm{p}=0.712)$ & $-0.189(p=0.484)$ \\
\hline Kyphosis x Sagittal Balance & $0.22(\mathrm{p}=0.89)$ & $0.140(\mathrm{p}=0.664)$ & $0.015(\mathrm{p}=0.940)$ & $0.076(\mathrm{p}=0.731)$ & $-0.172(p=0.523)$ \\
\hline Kyphosis x Sacral inclination & $0.025(\mathrm{p}=0.88)$ & $-0.014(\mathrm{p}=0.965)$ & $0.071(\mathrm{p}=0.724)$ & $0.036(\mathrm{p}=0.872)$ & $-0.067(p=0.806)$ \\
\hline Lordosis x Sagittal Balance & $0.051(\mathrm{p}=0.76)$ & $0.077(\mathrm{p}=0.813)$ & $0.047(\mathrm{p}=0.815)$ & $0.098(\mathrm{p}=0.655)$ & $-0.086(\mathrm{p}=0.753)$ \\
\hline Lordosis x Sacral inclination & $0.664(\mathrm{p}<0.001)^{*}$ & $0.665(\mathrm{p}=0.018)^{*}$ & $0.732(\mathrm{p}<0.001)^{*}$ & $0.667(\mathrm{p}=0.001)^{*}$ & $0.667(\mathrm{p}=0.005)^{*}$ \\
\hline Sagittal Balance $x$ Sacral inclination & $0.325^{*}(\mathrm{p}=0.04)$ & $0.337(\mathrm{p}=0.284)$ & $0.308(\mathrm{p}=0.119)$ & $0.345(\mathrm{p}=0.107)$ & $0.253(\mathrm{p}=0.345)$ \\
\hline
\end{tabular}

in boys $\left(43,6^{\circ}\right.$ and $35,7^{\circ}$, respectively) than in girls $\left(42,1^{\circ}\right.$ and $32,5^{\circ}$, respectively). However, Noll, et al. [17] in postural evaluation of school children aged 11 to 16 years found significant difference between the sexes only for body balance variables $(\mathrm{p}=0,001)$ and dorsal kyphosis $(\mathrm{p}=0,006)$.

In contrast, the present study did not find differences between the sexes (Table 1). These results corroborate with the study by Giglio and Volpon [18] also with the population of children and adolescents did not show differences between the female and male sexes with respect to the spine curvatures.

Regarding the sagittal balance parameter, which showed a significant and moderate correlation with the sagral inclination $(\mathrm{r}=$ $0,325 ; p=0,04)$, no study was found that showed the measure of this angle in this population. In the current study, the measurement of the sagittal balance angle presented a negative value, both for the sample's division in sex and in the age group, which may suggest posterior trunk displacement and pelvic antepulsion in the children and adolescents in question.

According to Asher [19] the posture varies according to the growth phases and body segments. The author also considers that a lumbar hyperlordosis is physiological in children of six years of age and is associated with anterior pelvic tilt, as a form of pursuit or body balance, which should decrease with its development. These changes are still present during adolescence, varying according to sex, due to puberty.

It is suggested that the angulations of the lumbar segment of the spine increase steadily in the cephalo-caudal direction during the growth period, which includes the values of the sacral inclination that tend to increase as the age increases [20,21]. A study by Giglio and Volpon [18] performed in individuals in the age group of 5-20 years showed that the kiphotic (T1-T12 angle) and lordotic (L1-L5 angle) curves of the spine increase linearly with age, without differences between the female and male sexes. The results of the present work don't agree with these previous studies, besides that the angular values are smaller when we observed the population of 12-18 years in relation to those of 11 years old, and wasn't observed significant differences between sample stratifications, both for sex and age group (Table 1).

Some research has sought to relate spinal alignment behavior during peak growth according to sex. One of these studies found that the thoracic kyphosis was lower in the girls $(p=0,023)$, the posterior inclined T1 segment was higher $(\mathrm{p}<0,001)$, and the T3-T11 levels were more posterior inclined $(\mathrm{p}<0,05)$ compared to boys at all stages of development, that is, before, during and after peak growth [22]. Another study [23] also identified a greater inclination of the dorsal curvature of the spine during the peak of growth, being this difference more significant in the final phase of puberty, especially the female with higher values in the spinal-sacral angle, in the spine inclination and dorsal tilt of T1 and T12-L2 than males $(\mathrm{p}<0,05)$.

Vedantam, et al. [10] when comparing these variables among adolescents with $13 \pm 8$ years old and adult subjects of $57 \pm 11$ years, lumbar lordosis values are similar (64 \pm 10 in both groups), in contrast, thoracic kyphosis presented a slightly higher value in the adolescent grupo $\left(38^{\circ} \pm 10^{\circ}\right.$ vs. $\left.34^{\circ} \pm 11^{\circ}\right)$ with $\mathrm{p}=0,042$. Asymptomatic adult individuals also describe variation between spinopelvic parameters, as emphasized by Kim, et al. [6] who compared two groups: group 1 of young adults, mean age 21,2 years, and group 2 of older individuals, mean age 63,8 years, and verified statistically significant difference between groups 1 and 2 for thoracic kyphosis and total lumbar lordosis (T12-S1), respectively, $21,1^{\circ} \pm 7,8^{\circ}$ versus $30,1^{\circ} \pm 8,6^{\circ}$ and $52,2^{\circ} \pm 9,2^{\circ}$ versus $57,3^{\circ} \pm 8,8^{\circ}$.

There is also a disagreement in the literature between the relationship of factors such as age and sex with the angles of lumbopelvic alignment, such as the study by Been and Kalichman [24], which still shows inconclusive evidence regarding the relation of lumbar lordosis angle and the variables cited.

The sagittal spine alignment variables evaluated in this study show values that are now approaching and now differ from other studies 
performed with the same population $[9,10,12]$. An element that can justify different results in the same population is the choice of the method of analysis of the alignment angles of the spine, the latter studies $[6,10,22,23]$ being distinct from Giglio and Volpon [18], Ghandhari, et al. [11] and the present study.

\section{Conclusion}

There was no difference for thoracic kyphosis, lumbar lordosis, sagittal balance and sacral inclination stratifying the sample in sex and age group. A correlation was observed between sacral inclination and lumbar lordosis, for all the stratifications of the sample, and also with the sagittal balance analyzing the total sample.

\section{References}

1. Vaz G, Roussouly P, Berthonnaud E, Dimnet J (2002) Sagittal morphology and equilibrium of pelvis and spine. Eur Spine $J$ 11: 80-87. [Crossref]

2. Gelb DE, Lenke LG, Bridwell KH, Blanke K, McEnery KW (1995) An analysis of sagittal spinal alignment in 100 asymptomatic middle and older aged volunteers. Spine (Phila Pa 1976) 20: 1351-1358. [Crossref]

3. Dolphens M, Cagnie B, Vleeming A, Vanderstraeten G, Coorevits P, et al. (2012) A clinical postural model of sagittal alignment in young adolescents before age at peak height velocity. Eur Spine J 21: 2188-2197. [Crossref]

4. Habibi Z, Maleki F, Meybodi AT, Mahdavi A, Saberi H (2014) Lumbosacral sagittal alignment in association to intervertebral disc diseases. Asian Spine J 8: 813-819. [Crossref]

5. Gardocki RJ, Watkins RG, Williams LA (2002) Measurements of lumbopelvic lordosis using the pelvic radius technique as it correlates with sagittal spinal balance and sacral translation. Spine J 2: 421-419. [Crossref]

6. Kim YB, Kim YJ, Ahn YJ, Kang GB, Yang JH, et al. (2014) A comparative analysis of sagittal spinopelvic alignment between young and old men without localized disc degeneration. Eur Spine J 23: 1400-1406. [Crossref]

7. Jackson RP, Peterson MD, McManus AC, Hales C (1998) Compensatory spinopelvic balance over the hip axis and better reliability in measuring lordosis to the pelvic radius on standing lateral radiographs of adult volunteers and patients. Spine (Phila Pa 1976) 23: 1750-1767. [Crossref]

8. Marty C, Boisaubert B, Descamps H, Montigny JP, Hecquet J, et al (2002) The sagittal anatomy of the sacrum among young adults, infants, and spondylolisthesis patients. Eur Spine J 11:119-125. [Crossref]

9. Mac-Thiong JM, Labelle H, Berthonnaud E, Betz RR, Roussouly P (2007) Sagittal spinopelvic balance in normal children and adolescents. Eur Spine J 16: 227-234. [Crossref]
10. Vedantam R, Lenke LG, Keeney JA, Bridwell KH (1998) Comparison of standing sagittal spinal alignment in asymptomatic adolescents and adults. Spine (Phila Pa 1976) 23: 211-215. [Crossref]

11. Ghandhari H, Hesarikia H, Ameri E, Noori A (2013) Assessment of normal sagittal alignment of the spine and pelvis in children and adolescents. Biomed Res Int 2013: 1-8. [Crossref]

12. Mac Thiong JM, Labelle H, Roussouly P (2011) Pediatric sagittal alignment. Eur Spine J 20 Suppl 5: 586-590. [Crossref]

13. Mac Thiong JM, Berthonnaud E, Dimar JR, Betz RR, Labelle H (2004) Sagittal alignment of the spine and pelvis during growth. Spine (Phila Pa 1976) 29: 1642-1647. [Crossref]

14. Fleiss RL (1986) The design and analysis of clinical experiments. New York: John Wiley and Sons.

15. Hopkins WG (2000) Measures of reliability in sports medicine and science. Sports Med 30: 1-15. [Crossref]

16. Masharawi Y, Kjaer P, Manniche C, Bendix T (2012) Lumbar sagittal shape variation vis-à-vis sex during growth: a 3 -year follow-up magnetic resonance imaging study in children from the general population. Spine (Phila Pa 1976) 37: 501-507. [Crossref]

17. Noll M, Rosa B, Candotti C, Furlanetto T, Gontijo K, et al. (2012) Alterações Posturais em Escolares do Ensino Fundamental de uma Escola de Teutónia. Cienc Mov 2: 33-42.

18. Giglio CA, Volpon JB (2007) Development and evaluation of thoracic kyphosis and lumbar lordosis during growth. J Child Orthop 1: 187-193. [Crossref]

19. Ascher C (1976) Variações da postura na criança. São Paulo: Manole.

20. Kamaci S, Yucekul A, Demirkiran G, Berktas M, Yazici MM (2015) The Evolution of Sagittal Spinal Alignment in sitting position during childhood. Spine (Phila Pa 1976) 40: E787-E793. [Crossref]

21. Schlösser TPC, Vincken KL, Rogers K, Castelein RM, Shah SA (2015) Natural sagitta spino-pelvic alignment in boys and girls before, at and after the adolescent growth spurt. Eur Spine J 24:1158-1167. [Crossref]

22. Janssen MM, Drevelle X, Humbert L, Skalli W, Castelein RM (2009) Differences in male and female spino-pelvic alignment in asymptomatic young adults: a threedimensional analysis using upright low-dose digital biplanar X-rays. Spine (Phila Pa 1976) 34: E826-E832. [Crossref]

23. Wang W (2015) Are there gender differences in sagittal spinal pelvic inclination before and after the adolescent pubertal growth spurt?. European Spine Journal 24: 11681174.

24. Been E, Kalichman L (2014) Lumbar lordosis. Spine J 14: 87-97. [Crossref]

Copyright: (C2018 Mesquita PVD. This is an open-access article distributed under the terms of the Creative Commons Attribution License, which permits unrestricted use, distribution, and reproduction in any medium, provided the original author and source are credited. 